\title{
Tempo e história: \\ algumas aproximações acerca do presente em Walter Benjamin e em Martin Buber
}

\author{
Monica Udler Cromberg*
}

Resumo: O Conceito de "presente" de Martin Buber e o de Walter Benjamin parecem equivaler-se. O de Buber é referido como "Gegenwart", termo que quer dizer tanto "presente" (temporal) como "presença", e o de Benjamin como "Jetzt=eit". Ambos implicam um tempo qualitativo e não linear e cronológico e consideram o presente como uma ruptura - seja na cadeia da causalidade, seja no determinismo das leis naturais e historicistas - e um entrecruzamento de temporalidades, onde o passado e $o$ futuro se fundem.

Palavras-chave: Martin Buber - Walter Benjamin - Presente - História - Tempo

Há pelo menos duas maneiras de falar da história: a do historiador e a do filósofo. O primeiro fala da história mas "esquece a dimensão do tempo". Quanto ao filósofo, tende a falar do tempo e "esquece a história". Procurando compreendê-los sem compartimentá-los, Buber e Benjamin valemse do conceito de presente.

Pode-se dizer que o "presente" (Gegenwart) é um conceito fundamental e central na filosofia dialógica de Martin Buber. O termo usado por ele para designá-lo, "Gegenwart", significa em alemão tanto "presença" como "presente" - "presente" não como adjetivo derivado de "presença" mas como substantivo que designa o tempo atual. O sentido dessa univocidade será crucial para o conceito de presente. O presente, como tempo, é o que está presente, como presença, e o que está presente é o que ins-

* Mestranda do Departamento de Letras da FFLCH-USP. 
taura o tempo presente e a atualidade ${ }^{1}$. À compreensão disso tudo, no entanto, é aqui necessária a passagem por outros conceitos-chave nos quais Buber baseia a constituição de sua filosofia.

Nesse sentido, sua obra capital, Ich und $D u$, "Eu e Tu", constrói-se sobre os pilares de duas palavras-princípio (Grundwort $)^{2}$ : Eu-Isso e Eu-Tu ${ }^{3}$. Buber chama "relação" somente o que há entre Eu e Tu; entre Eu e Isso há um "relacionamento". O âmbito dos verbos transitivos, das atividades que tenham algo como objeto funda o domínio do Isso; o reino do Tu não implica coisa alguma como objeto. "Aquele que diz Tu não tem coisa alguma por objeto (...) Na medida em que se profere o Tu, coisa alguma existe. $\mathrm{O}$ Tu não se confina a nada. Quem diz Tu não possui nada. Ele permanece em relação."4 $\mathrm{O}$ mundo do Isso é o mundo da e como experiência. Experienciar representa para Buber uma aproximação superficial às coisas, por mais que se saiba sobre elas, não importando de que natureza será esse conhecimento ou essa coisa, e um distanciamento do Tu. "Amontoado de informações" é tudo o que, em termos de conhecimento, podemos obter de algo com o qual nos relacionamos dentro do domínio do Eu-Isso. "O experimentador não participa do mundo. A experiência realiza-se 'nele' e não entre ele e o mundo." $" 5$

No entanto, quando acontece de entrarmos em relação com algo podendo ser um objeto, uma pessoa, um ser espiritual, uma obra de arte ou o que seja - não é com suas características que nos relacionamos - com as leis que o regem, a espécie ou categoria à qual pertence, sua composição, sua localização espaço-temporal, a carga emotiva que lhe atribuímos, a imagem visual que produz, etc. -, mas com ele mesmo; ele, que se fez agora Tu; ele, cuja totalidade implica uma identidade que está mais além da soma de todas as propriedades - extrínsecas e intrínsecas. A relação não se dá entre Eu e elas, mas entre Eu e uma totalidade que, para Buber, é muito mais que todas juntas ${ }^{6}$ : é "presença". Nenhum outro termo viria aqui representar tão bem o que se realiza no domínio da relação e a condição para que se realize. O Tu manifesta-se enquanto "presença", Gegenwart-termo que, como já disse, designa tanto "presença" como "presente", o tempo atual. O $\mathrm{Tu}$, portanto, manifesta-se enquanto presente, Gegenwart, sendo a presença, ao mesmo tempo, condição para que o presente se dê:

“O presente, não no sentido de instante pontual que não designa senão o término, constituído em pensamento, do tempo 'expirado' ou a apa- 
rência de uma parada nessa evolução, mas o instante atual e atualizado, dá-se somente quando existe presença (Gegenwärtigkeit), encontro, relação. Somente na medida em que o Tu se torna presente o presente se instaura." 7

Para Buber, o momento atual só pode ser chamado de presente se "merecer" a designação, ou seja, se houver de fato "presença" - que se poderá manifestar em qualquer pessoa, coisa, acontecimento (atual, passado ou futuro). Se o que se apresenta agora está destituído de atualidade, não será mais que passado ${ }^{8}$ :

"O Eu da palavra-princípio Eu-Isso, o Eu, portanto, com o qual nenhum Tu está face-à-face presente em pessoa, mas que é cercado por uma multiplicidade de 'conteúdos', tem só passado e de forma alguma presente. Em outras palavras, na medida em que o homem se satisfaz com as coisas que experiencia e utiliza, ele vive no passado e seu instante é privado de presença. Ele só tem diante de si objetos, e estes são fatos do passado.

"Presença (ou presente - Gegenwart) não é algo fugaz e passageiro, mas o que aguarda e permanece diante de nós. Objeto (Gegenstand) não é duração, mas estagnação, parada, interrupção, enrijecimento, desvinculação, ausência de relação, ausência de presença.

"O essencial é vivido na presença, as objetividades no passado."

A idéia de presença vinculada à de presente é essencial para o conceito de Walter Benjamin de presente, que para designá-lo usa o consagrado termo Jetztzeit - o "tempo do agora", às vezes traduzido também como "agoridade" . O Jetztzeit benjaminiano equivaleria ao Gegenwart buberiano uma vez que "é o absolutamente presente" 10 . O caráter monadológico do Jetztzeit, onde cada momento contém a história toda, parece coincidir com a exclusividade inclusiva do Gegenwart em Buber, que faz com que o presente, único e específico, inclua tudo o mais na sua presença, "apenas ele existe, mas não há abstração, tudo é visto à sua luz". Para Benjamin, o tempo é pleno de Jetztzeit e este permeia tanto o presente como o passado e o futuro, ou seja, tudo pode ser também visto à sua luz, tudo pode estar pleno de atualidade, dependendo apenas da Geistesgegenwart " - termo importante na filosofia de Benjamin relacionado ao Jetztzeit (e constituído do ter- 
mo Gegenwart) designando a "presença de espírito" ou "de consciência"e do reconhecimento da oportunidade de quebrar-se o tempo linear e "explodir-se o continuum da história"12.

Benjamin distingue o tempo do relógio do tempo dos calendários, isto é, o tempo "homogêneo e vazio"13 - que, como coloca Olgaria Matos, "é preenchido qual um recipiente, que acomoda indiferente acontecimentos que caem "dentro dele"14" - do tempo qualitativo, marcado pelo Jetztzeit e pela descontinuidade. "A história é objeto de uma construção cujo lugar não é o tempo homogêneo e vazio, mas um tempo saturado de 'agoras' (Jetztzeit)". Em oposição à linearidade e idealidade do tempo pode-se encontrar tanto na tradição grega quanto na judaica o conceito de tempo qualitativo. Cabe recordar que os gregos acreditavam que o tempo envelhecia, visão que considera o tempo como um atributo do homem, como qualidade, e que, claro, é diametralmente oposta à de um "tempo homogêneo e vazio", exterior aos fatos que nele ocorreriam e à consciência que o perceberia. No judaísmo, o passado é vivido na rememoração (Eingedenken) da Torá e dos dias festivos, e o futuro, na espera do Messias, uma vez que no futuro "cada segundo é a porta estreita pela qual pode entrar o Messias"; o tempo aí não é vivido "nem como vazio, nem como homogêneo", e é cheio de "agora", de Jetztzeit (erfüllte Zeit). O tempo qualitativo é o tempo da tradição, que é, para Benjamin, a dimensão na qual se aloja a "aura" do tempo; tradição grega, tradição judaica, qualquer tradição considera e sempre considerou o tempo qualitativamente e utiliza o calendário para marcar o tempo como forma de aglutinar momentos de recordação (Eingedenken) coletiva, momentos de Jetztzeit, sendo o tempo "homogêneo e vazio" uma idealidade exclusiva da modernidade ${ }^{15}$.

$\mathrm{O}$ "agora" benjaminiano (Jetztzeit) é atualidade, é o tempo vivido, experienciado, não o ideado, apriorístico e transcedental, nem o encerrado em um acontecido cristalizado, imóvel, terminado. Neste horizonte, Jetztzeit (Benjamin) e Gegenwart (Buber) se aproximam. O Gegenwart é cheio de presença. Este conceito é crucial também para a concepção benjaminiana de história. Na recordação, uma via de mão dupla é percorrida: tanto o presente inunda o passado como o passado inunda o presente, e o passado torna-se, como diria Buber, "presente em pessoa" (leibhaft gegenübertreten). $O$ passado entra em relação com o presente e faz-se seu Tu. A memória involuntária ${ }^{16}$ é, aliás, tanto para Buber como para Benjamin, uma 
presentificação (Vergegenwärtigung) - como a que há no "salto de um tigre"17. O Jetztzeit, assim como o Gegenwart buberiano, rompe a linearidade do tempo. O tempo linear é o tempo dos vencedores da história naturalizada que precisa ser interrompido: "A continuidade da história é a dos opressores" e "a história dos oprimidos é uma descontinuidade"18. O presente não é para nossos pensadores um "instante pontual" (Buber) que separa o passado do futuro ou que constitui uma "transição" entre eles, tal como Benjamin critica na tese XVI, mas uma porta que se abre para a suspensão (Aufhebung) e a superação do tempo, uma porta que nos leva tanto ao passado como ao futuro e permite um entrecruzamento completo entre as temporalidades assim como inversões das relações de tempo ${ }^{19}$, permitindo ao passado estar "pleno de agora (Jetztzeit)" e fazer-se presente no presente. Esse entrecruzamento de temporalidades parece ter como condição a "destruição" do tempo linear e é um elemento que permeia toda a obra de Benjamin assim como está bastante presente e atuante na de Buber. Como exemplo dele em Benjamin, recordemos o tableaux "Notícia de uma morte" em Infância Berlinense ${ }^{20}$, onde, na experiência do dejá $v u$, o presente tem o caráter de uma recordação - o presente é um "eco" do passado- e o futuro "será visto não como normalmente o que vem até nós, mas o que já esteve entre nós, como uma espécie de passado que nos ultrapassou" ou como a "possibilidade do por-viver que perdemos (versäumen) no passado". Como exemplo desse entrecruzamento em Buber, a descrição do que ocorre no êxtase místico em termos de temporalidade e a instauração do Gegenwart:

"No êxtase, tudo o que é passado e tudo o que é futuro converge para o presente. $\mathrm{O}$ tempo se condensa; se apaga a linha que separa as eternidades; sobrevive unicamente o momento; o momento se faz eternidade. À sua luz una, tudo se mostra, aquilo que já foi e aquilo que virá a ser, individual e conjuntamente. Está presente, como a batida de um coração, e se torna perceptível como ela."21

Ao descrever o Gegenwart, Buber parece estar descrevendo precisamente o Jetztzeit. Além disso, ambos coincidem na noção de "iluminação", profana ou não, e de "embriaguez/êxtase" (Rausch), noções importantes também na obra de ambos autores; eis também aí retratado, nessa citação de Buber, o "tempo messiânico" a que Benjamin se refere reiteradamente e 
utiliza para definir o Jetztzeit - " o conceito do presente como um Jetztzeit que cintila com fagulhas do tempo messiânico"22. O tempo messiânico, o tempo do Juízo Final (tese III), é o tempo puramente qualitativo, que nada tem de contínuo e linear - é o tempo da eternidade, o tempo pleno (erfüllte Zeit). É por isso que Benjamin sempre sugere a "imobilização messiânica dos acontecimentos"23, implicando não apenas a idéia de "redenção", mas o caráter de tal redenção e a forma de alcançá-la.

Não é apenas implícita - assim como não é exclusivamente explícita - a utilização de conceitos teológicos na obra de Benjamin. Na tese I, ele afirma que a teologia deve ser quem move o fantoche do materialismo histórico, e que, se assim for, este ganhará sempre. Revela que, por ser hoje "pequena e feia", a teologia "não ousa mostrar-se". No entanto, ele próprio a "mostra", revelando os "cordéis que dirigem a mão do fantoche" e explicitando as referências teológicas, que, mais que referências, são antes, na obra de Benjamin e como ele próprio acaba aqui por deixar patente, sua base mesma. Segundo ele e nele, materialismo e teologia não só não se opõem e não são incompatíveis, como funcionam juntos - o que, aliás, possibilitou a existência de oxímoros tais como "iluminação profana" e "profeta do presente" ${ }^{24}$.

O mesmo jogo de implicitude e explicitude está presente em Buber, apesar de não podermos traçar nesse ponto uma plena coincidência entre os dois, uma vez que a obra de Benjamin tem, em primeiro plano, um cunho materialista e a de Buber, propriamente teológico. No entanto, Buber também se vale de conceitos da mística - principalmente a judaica, tal como Benjamin -, sobre os quais construirá sua filosofia. Sua concepção de presente é um deles, e o mesmo poderá ser dito de Benjamin. Não podemos abstrair-nos aqui do fato de que a comparação que estabeleço no presente trabalho visa dois judeus, aliás contemporâneos.

Outro conceito da teologia judaica do qual Buber se utiliza, e que nos é aqui extremamente pertinente para compreendermos a formação do conceito de presente em Buber e em Benjamin, é o de Umkehr - em hebraico, teshuvá, que poderia ser traduzido por: "retorno", "volta", "conversão", "inversão", "arrependimento". A teshuvá é, dentro dos moldes da religião mais exterior e moralista, a designação do arrependimento, da contrição, mas possui, na verdade, um sentido muito mais abrangente e profundo, assim como o tem a própria idéia de "arrependimento". Teshuvá marca o momen- 
to de um despertar e de um recordar-se. É nessa medida que quer dizer também retorno; é o momento do retorno da e à consciência. É o dar a meia volta e volver para o local de partida (umkehren), mais propriamente: para Si mesmo. A teshuvá interrompe o andamento e a linearidade da vida e suspende seu movimento centrífugo: configura uma ruptura seguida de uma inversão de sentido, uma conversão, que visa, aliás, ao repouso ${ }^{25} \mathrm{da}$ ipseidade. É com base no conceito de teshuvá que Buber coloca ${ }^{26}$ :

"O dogma do curso inelutável das coisas não deixa, porém, lugar à liberdade, nem para a sua revelação mais concreta, aquela cuja força serena modifica a face da terra: a conversão. Esse dogma desconhece o homem que pode vencer a luta universal pela conversão; aquele que rompe, pela conversão, as amarras dos impulsos de utilização; aquele que se liberta do fascínio da sua classe; aquele que, mediante a conversão, pode revolver, rejuvenescer, transformar quadros históricos os mais seguros. O dogma do decurso não te deixa no tabuleiro senão uma opção: observares as regras ou te retirares; aquele, porém, que realiza a conversão derruba todas as peças."

Tal colocação bem poderia ser de Benjamin, mas é de Buber, e evidencia novamente a coincidência de suas idéias, embora se apliquem a áreas diferentes. Lembremos a tese XVI:

"O materialista histórico não pode renunciar ao conceito de um presente que não é transição, mas pára no tempo e se imobiliza. Porque esse conceito define exatamente aquele presente em que ele mesmo escreve a história. O historicista apresenta a imagem 'eterna' do passado, o materialista histórico faz desse passado uma experiência única. Ele deixa a outros a tarefa de se esgotar no bordel do historicismo, com a meretriz 'era uma vez'. Ele fica senhor de suas forças, suficientemente viril para fazer saltar pelos ares o continuum da história".

Explodir o continuum da história, derrubar as peças do tabuleiro: "a única coisa fatal é crer na fatalidade"27; o viril, o que traz a redenção, a liberdade, seria romper a cadeia da causalidade que reina no mundo do Isso, seria libertar-se da história natural. "Interromper o curso do mundo era o desejo mais profundo de Baudelaire" 28 , assim como o de Benjamin ao co- 
locar isso, e como o de Buber - o de derrubar "o dogma do curso inelutável das coisas":

"A história das civilizações não é um estádio constante no qual os corredores, um após o outro, tenham que percorrer com coragem e inconscientemente o mesmo ciclo mortal. Um caminho inominado conduz através de suas ascensões e declínios. Não um caminho de progresso e de evolução; mas uma descida em espiral através do mundo subterrâneo do espírito e, também, uma ascensão para, por assim dizer, a região tão íntima, tão sutil e complicada que não se pode mais avançar, nem sobretudo recuar; onde há apenas a inaudita conversão: a ruptura."29

Nesse trecho de Buber, temos a presença de 3 conceitos fundamentais de Benjamin: 1) o da necessidade de se romper com o ciclo de repetição da história natural ${ }^{30}$, "essa meretriz" do "bordel do historicismo"31, "a projeção do passado no presente", a história dos vencedores, o ciclo infernal do eterno retorno; 2) a necessidade da invalidação da idéia de progresso da humanidade na história, que "é inseparável da idéia de sua marcha no interior de um tempo vazio e homogêneo" ("A crítica da idéia do progresso tem como pressuposto a crítica da idéia dessa marcha.") ${ }^{32}$; e 3) a aqui já discutida idéia de ruptura, que leva à imobilização do devir. Talvez seja necessário dizer que a imagem da espiral utilizada acima por Buber não equivale à criticada por Benjamin na tese XIII, uma vez que não está representando uma linearidade, mas uma ruptura ${ }^{33}$.

Tanto para Benjamin como para Buber, a idéia de repetição, assim como a de progresso, não são criadas senão por equiparações da história com as ciências naturais. Benjamin coloca: "A projeção do passado no presente, no âmbito da história, é análoga à substituição de configurações idênticas para as mudanças no âmbito de um mundo físico", o que é um "fundamento das ciências naturais"34. Mais que de "equiparação", Benjamin fala de uma "sujeição" da história ao "moderno conceito de ciência", que procede através de "leis" encontradas para explicar o curso dos eventos históricos e de outros métodos mais sutis. Benjamin critica o fatalismo das "leis puras da história", que seria uma "projeção do passado no presente" que garantiria a repetição do ciclo da vitória dos dominadores e minimizaria a vontade e a prática humanas, como se essas fossem forças apenas determinadas e não determinantes. Buber, igualmente, adverte do perigo de aprisi- 
onar-se a pessoa na história 35 e no mundo do Isso, que é o "reino absoluto da causalidade" 36 , através da crença em "leis" que atuem no domínio do devir como fazem no físico; essas "leis" constituem para Buber os deuses da modernidade, que determinam desde seu Olimpo o que será sem deixar escolha ao homem senão os obedecer - voluntária ou rebeldemente ${ }^{37}$. Além disso, Buber coloca ${ }^{38}$ :

"O pensamento biologista e o pensamento historicista de nosso tempo, por mais diferentes que possam parecer um do outro, colaboram para formar uma fé na fatalidade mais tenaz e angustiante que todas as outras. (...) Quer se trate da 'lei vital' de uma luta universal, na qual cada um deve combater ou renunciar à vida; quer se trate da 'lei psíquica' de uma concepção da pessoa psíquica unicamente baseada em instintos utilitários, inatos; quer se trate de 'lei social', de um processo social inevitável, onde vontade e consciência são meros epifenômenos; ou da 'lei cultural' de um dever inalterável e constante de uma gênese e de um ocaso dos quadros históricos; sob todas essas formas e outras mais, o que significa é que o homem está ligado a um dever inevitável contra o qual ele não lutaria senão no seu delírio."

Lidar com a história da mesma forma que com fenômenos do domínio natural é vê-la como um aglomerado de fatos (segundo Benjamin o procedimento do historicismo é "aditivo" ${ }^{39}$ ), de objetividades, de Isso+Isso+Isso... Segundo Buber, "todo esquema do decurso consiste somente em ordenar como história o nada-mais-senão-passado, os acontecimentos isolados do mundo, a objetividade (...) A profecia baseada na objetividade tem valor somente para quem ignora a presença". A falta de Gegenwart, a falta de Jetztzeit, eis o que constitui o "mausoléu da história", o "amontoado de ruínas" que "cresce até o céu" de que nos fala Benjamin na tese IX, onde analisa o quadro de Klee Angelus Novus ${ }^{40}$. É o que coloca Buber: “... podese perceber claramente na história um aumento progressivo do mundo do Isso", uma acumulação de fetiches. Para Buber, a verdadeira e crucial demarcação é entre Gegenwart e Gegenstand, entre Presença/Presente e Objeto $^{41}$, não esquecendo que, para Buber, objetos são de per si fatos do passado (sem atualidade, sem presença) ${ }^{42}$. Afinal, se o passado não for pleno de Jetztzeit, se não tiver presença e atualidade, se não estiver nos dizendo algo e se relacionando conosco, será um passado cristalizado e morto. Ali- 
ás, na tese VI lê-se: "Articular historicamente o passado não significa conhecê-lo 'como de fato foi'. Significa apropriar-se de uma reminiscência, tal como ela relampeja no momento de um perigo." Conhecer o passado "como de fato foi" não interessa ao materialismo histórico de Walter Benjamin; interessa conhecer a RELAÇÃO dele com o presente e com outros eventos e momentos históricos: interessam as constelações que formam. Como escreve Olgaria Matos: "Cada palavra, objeto ou evento precisa liberar-se do 'mausoléu da história', do peso de um sentido único e objetivo, isto é, irreversível." A história de sentido único é a História Universal do historicismo, é a "meretriz do 'era uma vez" " de que fala Benjamin na tese XVI: a história como objeto, a que é a mesma para todos e em qualquer tempo, a que se expõe absolutamente e em toda sua literalidade, a mercadoria, o fetiche; não a história como metáfora, como imagem dialética: que como se lê em Fisiognomia da Metrópole moderna, de Willi Bolle - nos permite ver "na fisionomia de 'outra' época a do nosso tempo"43.

A visão historicista da história, relacionando-se com os fatos como se fossem objetos (Gegenstand) e objetividades, lida com um passado morto, um presente morto, uma história morta, que só o que faz é refletir-se e projetar-se indefinidamente, o que não passa de um pesadelo mórbido e fantasmagórico. Em Passagenwerk Benjamin escreve: "a modernidade carrega a antigüidade como um mau espírito (wie einen $\mathrm{Alb}$ ) que teria vindo importuná-la em seu sono"44. Benjamin está aqui se valendo da formação da palavra "pesadelo" em alemão: Albtraum, da qual Traum significa "sonho", e $A l b$ ou $A l p$, um demônio, fantasma que à noite vem se postar no peito de quem dorme, provocando pesadelos. Entretanto, diz-se que esse espírito perde seu poder quando é chamado pelo seu verdadeiro nome, o que, numa coincidência no mínimo interessante, faz Buber valer-se da mesma imagem para falar da mesma opressão dos escombros e fantasmagorias da objetividade sem atualidade:

“Assim como é possível dominar um incubo (Alb) chamando-o pelo seu verdadeiro nome, assim também o mundo do Isso, que ainda há pouco esmagava com sua força espantosa a fraca força do homem, é constrangido a submeter-se àquele que o conhece em seu ser (...). Mas como poderia ser capaz de interpelar o incubo $(A l b)$ pelo seu nome aquele que no seu íntimo leva um fantasma, isto é, o Eu carente de atualidade? ..."45 
Como pode, no entanto, a humanidade viver em meio a tantos destroços, tantos fantasmas, tanta repetição? É que o mesmo se reveste sempre de novas faces, de novos trajes; é o "sempre novo e sempre mesmo": "A fisionomia do mundo (...), justamente no que há de mais novo, não muda

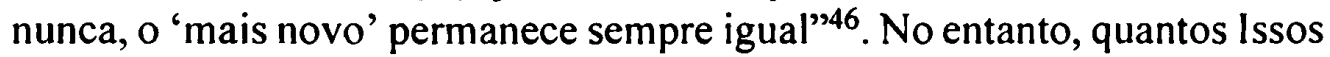
são necessários para se formar um Tu? A carência de atualização, de presença/presente real, é remediada por meio da compulsão do "Novo", enfatizada por Willi Bolle ${ }^{47}$ ao comentar os primeiros esboços da Obra das Passagens: "A Modernidade sob o signo da Moda-Cadáver: uma cultura que vive obcecada pela fantasmagoria do Novo, a compulsão de ter que produzir, a qualquer custo, o 'Novo' - um novo que é incessantemente desvalorizado por um novo mais novo ... É o retrato da Modernidade como 'tempo infernal'".

Enquanto o Jetztzeit não se faça legível e não se possa atualizar o instante, não se poderá sair das malhas do "sempre novo e sempre mesmo" para descobrir o sempre mesmo e sempre novo. Pois a atualidade é sempre ela mesma e é sempre renovada, de maneira, no entanto, inversa à que se dá com as ruínas da Novidade. Quando, no tempo, em plena linearidade temporal, chamamos o momento pelo seu verdadeiro nome, a ruptura se instaura, o Jetztzeit se faz legível e nos tornamos "profetas do presente" ${ }^{48}$, ou seja, lemos no presente seus sinais, recebemos suas mensagens, dialogamos com ele, entramos em relação. Entretanto, fortes obstáculos impedem a leitura. Em Do diálogo e do dialógico, de Buber, lê-se ${ }^{49}$ :

"Cada um de nós está preso em uma couraça, cuja tarefa é repelir os signos. Signos nos acontecem sem cessar. Viver significa ser alvo da palavra dirigida; nós só precisaríamos tornar-nos presentes, só precisaríamos perceber. Mas o risco nos é por demais perigoso, trovões silenciosos parecem ameaçar-nos de aniquilação: e aperfeiçoamos, de geração em geração, $o$ aparato de defesa. Toda a nossa ciência nos assegura: 'Sê tranqüilo, tudo acontece da forma que tem que acontecer, mas nada é dirigido a ti; este é simplesmente 'o mundo', tu podes vivenciá-lo como queres, mas o que quer que seja que em ti dele faças, provém de ti somente; nada é exigido de ti, a palavra não te é dirigida, tudo é silêncio.'

Cada um de nós está preso em uma couraça que, graças à força do hábito, deixa logo de sentir." 
Buber parece estar se referindo precisamente à acedia a que Benja$\min$ tanto se refere. Nas palavras de Willi Bolle ${ }^{50}$ :

"Trata-se da 'inércia do coração', a acedia medieval e barroca, redescoberta por Benjamin entre seus contemporâneos. A rotina das percepções leva a um encouraçamento emocional; e o medo de ser vulnerável, a um fazer as pazes com os choques do cotidiano."

Claramente está-se falando da mesma coisa, o que seria interessante se não fosse assustador. Benjamin cita Proust ${ }^{51}$ :

"Todos nós não temos tempo para viver os verdadeiros dramas para os quais estávamos destinados. É isto que faz envelhecer. Nada mais. As rugas e sulcos no nosso rosto são as assinaturas das grandes paixões, os vícios e impulsos que nos faziam apelo - mas nós, os senhores, não estávamos em casa."

O mesmo impacto que se tem ao ler essas palavras se repete quando Buber continua o trecho em que trata da couraça dizendo:

"São apenas instantes que atravessam a couraça e que incitam a alma à receptividade. E quando tal instante agiu sobre nós e nos tornamos então atentos, perguntamo-nos: 'Que é que aconteceu aí de peculiar? Não era algo semelhante ao que me acontece todos os dias?', então podemos nos responder: 'Realmente, nada de peculiar aconteceu, é assim todos os dias, só que nós não estamos aí presentes todos os dias."

Abstract: The concepts of "present" by Martin Buber and Walter Benjamin seem to be equivalent. Buber's is refered as "Gegenwart", a word that means both "present" (in a temporal sense) and "presence". Benjamin's is refered as "Jetztzeit". Both them implicate a qualitative time, not a linear, chronological one, and regard the present as a breakthrough - as much in the chain of causality as in the determinism of natural and historicist laws - and a crossroad of temporalities, where past and future join together. Key words: Martin Buber - Walter Benjamin - Present - History - Time 


\section{Notas}

' Assim como o termo Gegenwart é univoco na língua alemã, o mesmo ocorre com o termo "atualidade" aqui empregado, que possui tanto um sentido temporal como denota o que se opõe à virtualidade - o que está em ato, atualizado.

${ }^{2}$ Uma palavra-princípio não é um vocábulo mas sim um par de vocábulos que funda uma existência. Cf. Introdução de $E u$ e Tu, por Newton Aquiles von Zuben. Cf. Martin BUBER, Eu e Tu, São Paulo, Ed. Moraes, s.d.

${ }^{3} \mathrm{O}$ Eu da palavra-princípio Eu-Isso - podendo Isso (es) ser substituído por Ele (er) ou Ela (sie) - não é o mesmo Eu da palavra-princípio Eu-Tu. "A palavraprincípio Eu-Tu só pode ser proferida pelo ser na sua totalidade. A palavra-princípio Eu-Isso não pode jamais ser proferida pelo ser na sua totalidade." (Cf. Martin Buber, Eu e Tu, op. cit., pp. 3 e 4.)

${ }^{4}$ Cf. Martin BUBER, Eu e Tu, op. cit., p. 5.

${ }^{s}$ Cf. Martin BUBER, Eu e Tu, op. cit., p. 6.

${ }^{6}$ Isso ocorre sem que se deva, aliás, abstrair qualquer uma delas para que possa se manifestar o Tu. As qualidades não constituem o Tu, "assim como a melodia não se compõe de sons, nem os versos de vocábulos".

${ }^{7}$ Cf. Martin BUBER, Eu e Tu, op. cit., p. 14; ou M. Buber, Ich und Du, Heidelberg, Verlag Lambert Schneider, 1997, pp. 19 e 20: "Gegenwart, nicht die punkthafte, die nur den jeweilig im Gedanken gesetzten Schluß der 'abgelaufenen' Zeit, den Schein des festgehaltenen Ablaufs bezeichnet, sondern die wirkliche und erfüllte, gibt es nur insofern, als es Gegenwärtigkeit, Begegnung, Beziehung gibt. Nur dadurch, daß das Du gegenwärtig wird, entsteht Gegenwart."

${ }^{8}$ Idem, ibidem. "Das Ich des Grundworts Ich-Es, das Ich also, dem nicht ein Du gegenüber leibt, sondern das von einer Viel heit von "Inhalten"umstanden ist, hat nur Vergangenheit, keine Gegenwart. Mit anderm Wort: insofern der Mensch sich an den Dingen genügen läßt, die er erfährt und gebraucht, lebt er in der Vergangenheit, und sein Augenblick ist ohne Präsenz. Er hat nichts als Gegenstände; Gegenstände aber bestehen im Gewesensein.

"Gegenwart ist nicht das Flüchtlige und Vorübergleitende, sondern das Gegenwartende und das Gegenwährende. Gegenstand ist nicht die Dauer, sondern der Stillstand, das Innehalten, das Abbrechen, das sich Versteifen, die Abgehobenheit, die Beziehunglosigkeit, die Präsenzlosigkeit. 
"Wesenheiten werden in der Gegenwart gelebt, Gegenständlichkeiten in der Vergangenheit."

${ }^{9}$ Como, por exemplo, por Haroldo de Campos.

${ }^{10}$ Cf. Olgária MATOS, Os Arcanos do Inteiramente Outro, São Paulo. Ed. Brasiliense, 1995.

"Cf. Norbert BOLZ, "Onde encontrar a diferença entre uma obra de arte e uma mercadoria?", in Revista USP, Dossiê Walter Benjamin no. 15, São Paulo, Edusp, 1992.

${ }^{12}$ Cf. Walter BENJAMIN, "Sobre o Conceito de História", in Magia e Técnica, Arte e Política, São Paulo, Ed. Brasiliense, 1987, tese XV, p. 230.

${ }^{13}$ Idem, ibidem, tese XIV, p. 229.

${ }^{14}$ Cf. Olgária MATOS, op. cit., p. 31.

${ }^{15}$ A modernidade é a única em fazer do tempo uma evolução e da história um progresso. "Assim, os calendários não marcam o tempo do mesmo modo que os relógios. Eles são monumentos de uma consciência histórica da qual não parece mais haver na Europa, há cem anos, o último vestígio." Cf. Walter BENJAMIN, "Sobre o Conceito de História", in Magia e Técnica, Arte e Política, São Paulo, Ed. Brasiliense, 1987, tese XV, p. 230.

16 "História em sentido estrito ", escreve Benjamin, "é uma imagem da memória involuntária". Cf. G.S. I, 3, Suhrkamp, 1971, p. 243. Também: "Um tempo fora da história (Geschichtlos) como memória involuntária". Cf. W. Benjamin, "Über einige Motive bei Baudelaire", in Illuminationen, Frankfurt, Suhrkamp, 1980, p. 219.

${ }^{17}$ Cf. Walter BENJAMIN, "Sobre o Conceito de História", in Magia e Técnica, Arte e Política, São Paulo, Ed. Brasiliense, 1987, tese XIV, p. 230.

${ }^{18}$ Cf. Walter Benjamin, G.S. I, Frankfurt, Suhrkamp, 1974, p. 658.

${ }^{19}$ Cf. Howard STERN, "Umkehrung des déjà vu: Zu einem Text der 'Berliner Kindheit", in Text +Kritik, Zeitschrift für Literatur 31/32 Walter Benjamin, München, 1979.

20 "...o presente parece ressoar apenas como um eco". Cf. Walter BENJAMIN, Rua de Mão Única, São Paulo, Ed. Brasiliense, 1987, p. 89.

${ }^{21}$ Cf. Martin Buber, Die Legende des Baalschem, Zürich, Manesse Verlag, 1988, p. 23: "In der Eckstase rückt alles Vergangene und alles Zukünftige zur Gegenwart zusammen. Die Zeit verschrumpft, die Linie zwischen den Ewigkeiten verschwindet, 
einzig der Augenblick lebt, und der Augenblick ist die Ewigkeit. In seinem unzersplitterten Licht erscheint alles, was war und was sein wird, einfach und gesammelt. Es ist da, wie ein Herzschlag da ist, und wird vernehmbar wie er."

${ }^{22}$ Cf. Walter BENJAMIN, "Zum Bildes Prousts", in Illuminationen, Frankfurt, Suhrkamp, 1980; Walter BENJAMIN, Coletânea Para uma Imagem de Proust, Caracas, Monte Ávila, s.d.; e W. BENJAMIN, "Sobre o conceito de História" apêndice I, in Magia e Técnica, Arte e Politica, São Paulo, Ed. Brasiliense, 1987.

${ }^{23}$ Cf. Walter BENJAMIN, "Sobre o Conceito de História", in Magia e Técnica, Arte e Política, São Paulo, Ed. Brasiliense, 1987, tese XVII.

${ }^{24}$ Cf. Walter BENJAMIN, Illuminationen, Frankfurt, Suhrkamp, 1980.

${ }^{25}$ Cabe aqui notar que a raiz da palavra teshuvá - que é o verbo "voltar" - é a mesma do verbo "sentar-se", "permanecer", "ficar" e da palavra shabat, o sétimo dia da semana judaica, o dia de descanso, que justamente quebra o tempo linear da semana e instaura um tempo sagrado, qualitativo, que "pára no tempo e se imobiliza".

${ }^{26}$ Cf. Martin BUBER, Eu e Tu, op. cit., p. 26; ou Ich und Du, Heidelberg, Verlag Lambert Schneider, 1997, p. 70: "Das Dogma des Ablaufs läßt keinen Raum für die Freiheit, keinen für ihre allerrealste Offenbarung, dleren gelassene Kraft das Angesicht der Erde ändert : die Umkehr. Das dogma kennt den Menschen nicht, der den Allkampf durch die Umkehr überwindet; der das Gespinnst der Gebrauchstriebe durch die Umkehr zerreißt; der sich dem Bann der Klasse durch die Umkehr enthebt; - der durch die Umkehr die sicheren Geschichtsgebilde aufrührt, verjüngt, verwandelt."

${ }^{27}$ Martin Buber, Eu e Tu, op. cit., p.

${ }^{28}$ Cf. Walter Benjamin, G.S. I, 3, Frankfurt, Suhrkamp, 1974, p.1243; e W. Benjamin, "Über einige Motive bei Baudelaire", in Illuminationen, op. cit., p. 219.

${ }^{29}$ Cf. Martin BUBER, Eu e Tu, São Paulo, Ed. Moraes, s.d., p. 65; e Martin Buber, Ich und Du, Heidelberg, Verlag Lambert Schneider, 1997, p. 68: "Die Geschichte der Kulturen ist nicht ein Stadion der Äonen, in dem ein Läufer nach dem andern munter und ahnungslos den gleichen Todeskreis zu durchmessen hätte. Durch ihre Auf-und Niedergänge führt ein namenloser Weg. Kein Weg des Fortschritts und der Entwicklung; ein Hinabstieg durch die Spiralen der geistigen Unterwelt, wohl auch ein Aufstieg zum innersten, feinsten, verschlungensten Wirbel zu nennen, wo es kein Weiter mehr und erst recht kein Zurück gibt, nur noch die unerhörte Umkehr: den Durchbruch." 
${ }^{30} \mathrm{Cf}$. Olgária MATOS, Os Arcanos do Inteiramente Outro, Cap. História e Repetição, São Paulo. Ed. Brasiliense, 1995; e o artigo da mesma autora "Da impossibilidade da repetição à compulsão à repetição: Walter Benjamin, $\mathrm{O}$ marxismo, a psicanálise", in Revista IDE, no.15, São Paulo, Sociedade Brasileira de Psicanálise de São Paulo, 1988.

${ }^{31}$ Cf. Walter BENJAMIN, "Sobre o Conceito de História", in Magia e Técnica, Arte e Política, São Paulo, Ed. Brasiliense, 1987, tese XVI.

${ }^{32}$ Cf. Walter BENJAMIN, "Sobre o Conceito de História", in Magia e Técnica, Arte e Política, São Paulo, Ed. Brasiliense, 1987, tese IX e XIII.

33 “A teoria, e, mais ainda, a prática da social-democracia foram determinadas por um conceito dogmático de progresso sem qualquer vínculo com a realidade. (...) era um processo essencialmente automático, percorrendo, irresistivel, uma trajetória em flecha ou em espiral." Cf. Walter BENJAMIN, "Sobre o Conceito de História", in Magia e Técnica, Arte e Política, São Paulo, Ed. Brasiliense, 1987, tese XIII.

${ }^{34}$ Cf. Walter Benjamin, G.S. I, 3, Frankfurt, Suhrkamp, 1974, p. 1231.

${ }^{35} \mathrm{Cf}$. Martin BUBER, Eu e Tu, op. cit., p. 49.

${ }^{36} \mathrm{Cf}$. Martin BUBER, Eu e Tu, op. cit., p. 59.

${ }^{37} \mathrm{Cf}$. Martin BUBER, Eu e Tu, op. cit., p. 66.

${ }^{38} \mathrm{Cf}$. Martin BUBER, Eu e Tu, op. cit., pp. 65 e 66.

${ }^{39}$ Cf. Walter BENJAMIN, "Sobre o Conceito de História", in Magia e Técnica, Arte e Politica, op. cit., tese XVII.

${ }^{40}$ Cf. Walter BENJAMIN, "Sobre o Conceito de História", in Magia e Técnica, Arte e Politica, op. cit., tese IX.

${ }^{41}$ Cf. Martin BUBER, Eu e Tu, op. cit., pp. 13 e 14; e Ich und Du, Heidelberg, Verlag Lambert Schneider, 1997, p. 19.

${ }^{42} \mathrm{Cf}$. Martin BUBER, Eu e Tu, op. cit., pp. 14 e15. “...na medida em que o homem se satisfaz com as coisas que experiencia e utiliza, ele vive no passado e seu instante é privado de presença. Ele só tem diante de si objetos, e estes são fatos do passado". Cf. M. Buber, Ich und Du, op. cit., p. 19.

${ }^{43}$ Cf. Willi Bolle, Fisiognomia da Metrópole Moderna, São Paulo, EDUSP, 1994, p. 109.

${ }^{44}$ Cf. Walter Benjamin, Passagenwerk, Suhrkamp, 1982, p. 470. 
${ }^{45}$ Cf. Martin BUBER, Eu e Tu, op. cit., p. 68; e Ich und Du, Heidelberg, Verlag Lambert Schneider, 1997, p. 71: “Wie man Gewalt über den Alp bekommt, wenn man ihm seinen wirklichen Namen zuruft, so muß sich die Eswelt, die sich eben noch unheimlich vor der kleinen Menschenkraft reckte, dem ergeben, der sie in ihrem Wesen erkennt (...) Wie aber möchte der die Gewalt aufbringen, den Alp beim Namen anzurufen, dem selbst im Innern ein Gespenst hockt-das entwirklichte Ich?"

${ }^{46}$ Cf. Walter Benjamin, GS, V, op. cit., 1010s.

${ }^{47}$ Cf. Willi Bolle, Fisiognomia da Metrópole Moderna, São Paulo, EDUSP, 1994, p. 136.

${ }^{48}$ Cf. Walter Benjamin, Illuminationen, op. cit.

${ }^{49}$ Cf. Martin Buber, Do diálogo e do Dialógico, São Paulo, Ed. Perspectiva, col. Debates, 1982, p. 43 e 44.

${ }^{50}$ Cf. Willi Bolle, Fisiognomia da Metrópole Moderna, São Paulo, EDUSP, 1994, p. 122 .

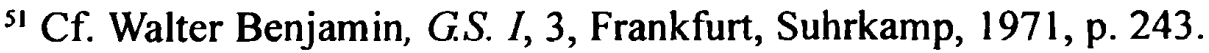




\section{Referências Bibliográficas}

1. ADORNO Über Walter Benjamin. Frankfurt, Tiedmann, 1970.

2. BENJAMIN, W. Magia e Técnica, Arte e Política. São Paulo, Ed. Brasiliense, 1987.

3. BENJAMIN, W. Rua de Mão Única. São Paulo, Ed. Brasiliense, 1987.

4. BENJAMIN, W. Illuminationen. Frankfurt, Suhrkamp, 1980.

5. BENJAMIN, W. Ursprung des Deutschen Trauerspiels. Frankfurt, Suhrkamp, 1963.

6. BENJAMIN, W. Passagenwerk. G.S., Frankfurt, Suhrkamp, 1974.

7. BENJAMIN, W. Origens do Drama Barroco Alemão. São Paulo, Ed. Brasiliense, 1984.

8. BENJAMIN, W. "Zum Bilde Prousts". In Illuminationen. op. cit.

9. BENJAMIN, W. Coletânea Para uma Imagem de Proust. Caracas, Monte Ávila, s.d.

10. BOLLE, W. Fisiognomia da Metrópole Moderna. São Paulo, EDUSP, 1994.

11. BOLLE, W. Tableaux Berlinois. São Paulo, dpto. de Letras, USP, 1985.

12. BOLZ, N. "Onde encontrar a diferença entre uma obra de arte e uma mercadoria?". In Revista USP, Dossiê Walter Benjamin no.15. São Paulo, Edusp, 1992.

13. BUBER, M. Ich und Du. Heidelberg, Verlag Lambert Schneider, 1997.

14. BUBER, M. Eu e Tu. São Paulo, Ed. Moraes, s.d.

15. BUBER, M. Do diálogo e do Dialógico. São Paulo, Ed. Perspectiva, col. Debates, 1982. 
16. BUBER, M. Die Legende des Baalschem. Zürich, Manesse Verlag, 1988.

17. GAGNEBIN, J.M. História e narrativa em Walter Benjamin. São Paulo, Ed. Perspectiva, 1994.

18. GAGNEBIN, J.M. "Walter Benjamin ou a história aberta". In Magia e Técnica, Arte e Política. São Paulo, Ed. Brasiliense, 1987.

19. MATOS, O. Os Arcanos do Inteiramente Outro. São Paulo. Ed. Brasiliense, 1995.

20. MATOS, O. "Amor e cidade, amor na cidade". In Na Sombra da Cidade. São Paulo, Ed. Escuta, 1995.

21. MATOS, $\mathrm{O}$. "Da impossibilidade da repetição à compulsão à repetição: Walter Benjamin, o marxismo, a psicanálise". In Revista $I D E$, no. 15. São Paulo, Sociedade Brasileira de Psicanálise de São Paulo, 1988.

22. STERN, H. "Umkehrung des déjà vu: Zu einem Text der 'Berliner Kindheit'". In Text + Kritik, Zeitschrift für Literatur 31/32 Walter Benjamin. München, 1979. 